\title{
Estimates of Grain Yield Losses Caused in Sorghum (Sorghum bicolor L. Moench) by Striga asiatica (L.) Kuntze Obtained Using the Regression Approach
}

\author{
M.J. VASUDEVA RAO, V.L. CHIDLEY* and L.R. HOUSE** \\ International Crops Research Institute for the Semi-Arid Tropics, Patancheru, 502 324, A.P. \\ (India)
}

(Accepted for publication 30 August 1988)

\begin{abstract}
Vasudeva Rao, M.J., Chidley, V.L. and House, L.R., 1989. Estimates of grain yield losses caused in sorghum (Sorghum bicolor L. Moench) by Striga asiatica (L.) Kuntze obtained using the regression approach. Agric Ecosystems Environ., 25: 139-149.
\end{abstract}

Regression approach was used to predict sorghum grain yield losees from Striga asiatica (L.) Kuntze in the susceptible sorghum hybrid cultivar, $\mathrm{CSH} 1$, in India. Four hundred and eighty eight pairs of grain yield and Striga counts data obtained from 10 checkerboard trials were used in the regression analysis. Experiments were conducted at 6 locations in India and in some loca. tions over 3 years. The $R^{2}$ value of the best-fitted joint regression equation was 0.787 . Mean grain yield loss estimates ranged from 9.2 to $27.6 \%$ of the potential yield between locations with an average loas of $17.5 \%$ in the rainy season. In the post-rainy season the average loss was $25.2 \%$ with a range of 20.1-39.6\% across years. Potential loss estimates indicated the possibility of up to $98.6 \%$ crop loss at some locations in some years. Assuming only $10 \%$ of the hybrid sorghum crop area to be affected by the Striga infestation levels realized in these trials, it was predicted that, in India, about 53000 t of sorghum grain worth about U.S. $\$ 4.9$ million (approximately 67 million Indian rupees) is being lost every year.

\section{INTRODUCTION}

Striga asiatica (L.) Kuntze, a phanerogamic root parasite of several cereals, is a significant yield reducer of its host crops. Crop loss estimates obtained using appropriate statistical methodology are very few and inadequate in accurately predicting the produce lost because of this parasite. Loss estimates' of

*Prewent addrese: Department of Agricultural Botany, Univenity of Reading, Reading, Gt. Britain. - Present addres: SADCC/ICRISAT Regional Sorghum and Millet Improvement Program, P.B. 776, Bulawayo, Zimbabwe. 
sorghum yields from Striga face 3 major difficulties: (i) it is difficult to create control (uninfested) vs. infested contrasts; (ii) the number of Striga plants that emerge above ground represent an unknown and often variable percentage of the total number of Striga plants that actually parasitize the host's roots; (iii) the crop loss estimates are influenced by the intervening soil factors, the major ones being soil fertility and moisture. This study is the first report on the use of regression approach to obtain sorghum yield loss estimates from Striga asiatica utilizing the data on naturally-occurring variability in Striga infestation in a single sorghum cultivar.

\section{MATERIALS AND METHODS}

Emerged Striga counts and grain yields from 488 plots of CSH 1 (Coordinated Sorghum Hybrid 1), were collected in the advanced Striga resistance trials conducted in "Striga-sick" fields which had a good history of Striga occurrence every year. Trials were conducted at 6 locations in India. At Akola and Bijapur the trials were carried out over 3 years. In these trials a checkerboard layout (Vasudeva Rao, 1987) was used. In this layout, test entry plots (of different resistant test entries) are interspersed uniformly among check entry plots (of the same susceptible check entry) in such a way that each test entry plot is surrounded on all its 4 sides by check entry plots. This layout enables measurement of the intensity of Striga infestation to be made at regular points in the experimental area, thus generating information on variability of Striga intensities. Each plot had 5 rows of which the central 3 rows were used as the net plot to record observations on Striga counts and grain yield. Net plot sizes varied from 3 to $9 \mathrm{~m}^{2}$. between locations. Emerged Striga were counted 3 times in the season between flowering of sorghum and its harvest in order to include the Striga plants that emerged later in the season. The maximum of the 3 counts was used as the final count. Grain yield was measured as the weight of the sun-dried threshed grain from the net plot.

To obtain crop loss estimates at the national level, statewise figures for area and production of sorghum were used. However, as Striga is more serious on hybrid sorghums, the loss estimates were restricted only to that part of the sorghum production contributed by the hybrids. Statistics on statewise area and production of sorghum and the statewise coverage by hybrids were obtained from the publications of Ministry of Agriculture and Rural Reconstruction, Government of India, through the kind courtesy of the Project Coordinator (Sorghum), All India Sorghum Improvement Project, Hyderabad (Tables 1 and 4). Statistical data for the 3 years, viz. 1980/81, 1981/82, 1982/83, were used to coincide with the experimental data. 


\section{TABLE 1}

Area, production and productivity of sorghum in rainy and post-rainy seasons in important sorghum-growing states in India (average of 1980/81; 1981/82 and 1982/83 statistics)

\begin{tabular}{|c|c|c|c|c|c|c|c|c|c|}
\hline \multirow[t]{2}{*}{ State } & \multicolumn{3}{|c|}{ Rainy season } & \multicolumn{3}{|c|}{ Post-rainy season } & \multicolumn{3}{|l|}{ Total } \\
\hline & $\begin{array}{l}\text { Area } \\
\left(\times 10^{3} \mathrm{ha}\right)\end{array}$ & $\begin{array}{l}\text { Production } \\
\left(\times 10^{3} t\right)\end{array}$ & $\begin{array}{l}\text { Productivity } \\
\left(\mathrm{kg} \mathrm{ha}^{-1}\right)\end{array}$ & $\begin{array}{l}\text { Area } \\
\left(\times 10^{3} \mathrm{ha}\right)\end{array}$ & $\begin{array}{l}\text { Production } \\
\left(\times 10^{3} t\right)\end{array}$ & $\begin{array}{l}\text { Productivity } \\
\left(\mathrm{kg} \mathrm{ha}^{-1}\right)\end{array}$ & $\begin{array}{l}\text { Area } \\
\left(\times 10^{?} \mathrm{ha}\right)\end{array}$ & $\begin{array}{l}\text { Production } \\
\left(\times 10^{9} t\right)\end{array}$ & $\begin{array}{l}\text { Productivity } \\
\left(\mathrm{kg} \mathrm{ha}^{-1}\right)\end{array}$ \\
\hline Maharashtra & 2972.4 & 3121.2 & 1050.0 & 3581.8 & 1535.8 & 428.7 & 6554.2 & 4657.0 & 710.5 \\
\hline Andhra Pradesh & 1064.9 & 608.1 & 566.3 & 1004.4 & 628.6 & 625.8 & 2069.3 & 1231.7 & 595.2 \\
\hline Karnataka & 828.9 & 917.0 & 1106.3 & 1116.3 & 632.3 & 566.4 & 1945.2 & 1549.3 & 796.4 \\
\hline Madhye Pradesh & 2232.0 & 1707.2 & 764.8 & 28.4 & 21.5 & 757.0 & 2260.4 & 1728.7 & 764.7 \\
\hline Trmilnadu & 488.0 & 363.2 & 744.2 & 108.1 & 103.4 & 956.5 & 596.1 & 466.6 & 782.7 \\
\hline Other states & 2580.8 & 1252.3 & 485.2 & 166.8 & 170.5 & 1022.1 & 2747.6 & 1422.8 & 517.8 \\
\hline All India & 10167.0 & 7964.0 & 783.3 & 6005.8 & 3092.1 & 514.8 & 16172.8 & 11056.1 & 683.6 \\
\hline
\end{tabular}

Source: Government of India, 1984. 


\section{Statistical analysis}

Grain yield values were regressed over Striga counts. Square root and log transformations of Striga counts, log transformation of yield and untransformed data values of both the variables were used in different combinations to fit several regression equations. The regression equations fitted were of the linear and quadratic types, with and without trial effects, for individual trial data sets, on data combined across trials (assuming variable trial effects and constant rates of loss across trials, and assuming variable trial effects and variable rates of loss across trials). The equation with the best fit was

$$
y_{i j}=\mu_{i}+\beta_{1}\left(x_{1 j}-\bar{x}_{i}\right)
$$

where:

$y_{u}=$ yield of $j$ th plot in $i$ th trial; $\mu_{1}=$ effect of the $i$ th trial $=$ potential yield of the trial site if Striga was absent; $x_{i j}=S$ triga counts $\mathrm{m}^{-2}$ in $j$ th plot in ith trial; $\bar{x}_{i}=$ mean Striga counts of the ith trial; $\beta_{i} \approx$ rate of loss in yield with increasing Striga numbers in the $i$ th trial; $i=$ number of trials $=1 . . .10 ; j=$ number of plots in a trial.

This joint regression equation, based on the procedure described by Yates and Cochran (1938) and Digby (1979), gave an $R^{2}$ value of 0.787 and in the analysis of variance the regression source of variation was significant. Hence this equation was used in crop loss prediction in the different trials.

The minimum, maximum (potential) and the mean percent yield loss estimates were calculated at the observed minimum, maximum and mean Striga levels, respectively, for individual trials using the potential yield estimates $\left(\mu_{1}\right)$ as the base. The $\beta_{i}$ values were tested for statistical significance using their respective standard errors. All the crop loss estimates were restricted to the observed levels of Striga loads. Potential yield estimates $\left(\mu_{i}\right)$ were used as weights to obtain mean yield loss estimates across trials.

Based on the area covered by hybrid sorghum and percentage crop loss estimates, the estimates of loss of grain and the consequent monetary loss in rupees were calculated for individual states. The grain and monetary loss estimates were restricted to: (1) that part of the sorghum production that is contributed by the hybrids; (2) the rainy season when the hybrids are extensively cultivated; ( 3 ) the actual season and year when the loss percentages were estimated in individual states.

\section{RESULTS}

Significant variation was observed in Striga counts both between and within the trials (Table 2). At Akola and Bijapur, where trials were conducted for 3 successive years, variation was observed in Striga counts both between and 
TABLE 2

Variability for Striga asiatica infestations and grain yield in CSH 1 in 10 checkerboard trials

\begin{tabular}{|c|c|c|c|c|c|c|c|c|}
\hline \multirow[t]{2}{*}{ Location } & \multirow[t]{2}{*}{ Year } & \multirow{2}{*}{$\begin{array}{l}\text { No. of } \\
\text { plots }\end{array}$} & \multicolumn{3}{|c|}{ Striga counts $\left(\mathrm{m}^{-2}\right)$} & \multicolumn{3}{|c|}{ Grain yield ( $\mathrm{kg} \mathrm{ha}^{-1}$ ) } \\
\hline & & & Minimum & Maximum & Mean & Minimum & Maximum & Mean \\
\hline \multicolumn{9}{|l|}{ Rainy season } \\
\hline Akola & 1981 & 40 & 87 & 851 & 362 & 231 & 1449 & 805 \\
\hline Akola & 1982 & 40 & 4 & 253 & 45 & 444 & 2519 & 1307 \\
\hline Akola & 1983 & 110 & 17 & 333 & 143 & 444 & 3611 & 1415 \\
\hline B Sagar & 1981 & 39 & 0 & 120 & 40 & 0 & 1975 & 502 \\
\hline ICRISAT Centre & 1982 & 40 & 54 & 256 & 153 & 3022 & 5267 & 4041 \\
\hline Parbhani & 1982 & 40 & 10 & 76 & 27 & 667 & 3833 & 2131 \\
\hline Indore & 1982 & 39 & 6 & 651 & 251 & 62 & 3164 & 1506 \\
\hline Over all trials & & 348 & 0 & 851 & 145 & 0 & 5267 & 1624 \\
\hline \multicolumn{9}{|l|}{ Post-rainy season } \\
\hline Bijapur & 1981 & 40 & 4 & 82 & 33 & 17 & 1975 & 689 \\
\hline Bijapur & 1982 & 40 & 189 & 817 & 501 & 37 & 2407 & 805 \\
\hline Bijapur & 1983 & 60 & 1 & 210 & 71 & 0 & 833 & 223 \\
\hline Over all trials & & 140 & 1 & 817 & 183 & 0 & 2407 & 522 \\
\hline
\end{tabular}

within years. An examination of Striga counts across the plots within the trials failed to show any trend in Striga distributions. The highest mean and highest maximum Striga infestation levels were noticed at Bijapur in 1982 and at Akola in 1981, respectively. The Striga numbers recorded ha ${ }^{-1}$, in general, were very high, the highest maximum being equal to 8.5 million emerged Striga plants $\mathrm{ha}^{-1}$ recorded at Akola in 1981. The highest mean Striga level, recorded at Bijapur in 1982, was about 5 million Striga plants ha-1.

Significant variations were also noticed in grain yield between plots both across and within trials. ICRISAT Centre in 1982 registered the highest mean grain yield of $4041 \mathrm{~kg} \mathrm{ha}^{-1}$. However, all the other trials recorded medium to low grain yield levels.

The correlation coefficients between Striga counts and grain yield were negative in all 10 trials and significant in 7 of them (Table 3). All ten regression coefficients, $\beta_{i}$, were negative and 7 of them were statistically significant. High values of $\beta_{i}$ were recorded at Parbhani in 1982 and at Bijapur in 1981. The trial at ICRISAT Centre in 1982 with the highest potential yield estimate also recorded a significant negative regression coefficient, indicating that even in highyielding environments, Striga could significantly reduce yields. However, there was little consistency between potential yield estimates and regression coefficients, and between potential yield estimates and percentage crop loss esti- 
TABLE 3

Regremion parameten and eatimates of crop lose in CSH 1 cauned by Striga asiatica

\begin{tabular}{|c|c|c|c|c|c|c|c|c|}
\hline \multirow[t]{2}{*}{ Location } & \multirow[t]{2}{*}{ Year } & \multirow{2}{*}{$\begin{array}{l}r \text { between } \\
\text { Strige } \\
\left(M^{-2}\right) \text { and } \\
\text { grain yield } \\
\left(\mathrm{ha}^{-1}\right)\end{array}$} & \multirow[t]{2}{*}{$\mu_{1} \pm \mathbf{S E}$} & \multirow[t]{2}{*}{$\beta_{i} \pm \mathrm{SE}$} & \multirow[t]{2}{*}{$\begin{array}{l}\text { Significance } \\
\text { of } \beta_{i}\end{array}$} & \multicolumn{3}{|c|}{$\begin{array}{l}\text { Per cent yield kas at the lond } \\
\text { of Striga }\end{array}$} \\
\hline & & & & & & Minimum & Maximum & Mean \\
\hline \multicolumn{9}{|l|}{ Rainy soason } \\
\hline Akole & 1981 & -0.26 & $970.4 \pm 210$ & $-0.46 \pm 0.44$ & NS & 4.12 & 40.18 & 17.10 \\
\hline Akola & 1982 & $-0.49^{* *}$ & $1545.6 \pm 158$ & $-5.35 \pm 1.85$ & $\bullet$ & 1.52 & 87.57 & 15.44 \\
\hline Akola & 1983 & $-0.20^{\circ}$ & $1699.1 \pm 159$ & $-1.98 \pm 0.74$ & $*$ & 1.94 & 38.92 & 16.71 \\
\hline B Sagar & 1981 & -0.08 & $552.9 \pm 167$ & $-1.29 \pm 2.45$ & NS & 0.00 & 27.95 & 9.24 \\
\hline ICRISAT Centre & 1982 & $-0.43^{\circ \circ}$ & $4685.5 \pm 274$ & $-4.21 \pm 1.56$ & * & 4.89 & 22.98 & 13.77 \\
\hline Parbhani & 1982 & $-0.39^{\circ}$ & $2648.5 \pm 207$ & $-18.95 \pm 5.75$ & 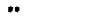 & 6.80 & 54.16 & 19.53 \\
\hline \multirow[t]{2}{*}{ Indore } & 1982 & $-0.55^{* *}$ & $2080.1 \pm 172$ & $-2.29 \pm 0.42$ & $\bullet$ & 0.62 & 71.64 & 27.62 \\
\hline & & & \multicolumn{2}{|c|}{ Weighted mean over all trials } & & 3.66 & 46.26 & 17.46 \\
\hline \multicolumn{9}{|l|}{ Post-rainy soason } \\
\hline Bijapur & 1981 & -0.58 & $1141.0 \pm 202$ & $-13.67 \pm 4.53$ & * & 5.15 & 98.60 & 39.66 \\
\hline Bijapur & 1982 & $-0.32^{\circ *}$ & $3012.6 \pm 320$ & $-1.21 \pm 0.58$ & 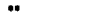 & 7.60 & 32.80 & 20.09 \\
\hline \multirow[t]{2}{*}{ Bijapur } & 1983 & -0.28 & $285.6 \pm 107$ & $-0.88 \pm 1.18$ & NS & 0.22 & 64.72 & 21.94 \\
\hline & & & \multicolumn{2}{|c|}{ Weighted mean over all trials } & & 6.50 & 51.77 & 25.24 \\
\hline
\end{tabular}

¿Significant at $P=0.05 ;{ }^{\circ-S i g n i f i c a n t ~ a t ~} P=0.1 ; \mathrm{NS}=$ not significant.

mates which indicated that yield loss from Striga could occur at all fertility levels.

The regression equation which included the trial effect and the rate of loss effect varying with the trial had a large $R^{2}$ value of 0.787 , indicating a high lovel of confidence associated with the crop loss estimates obtained using this regression equation.

In the post-rainy season, the mean loss was $25.2 \%$ with $17.5 \%$ in the rainy season (Table 3 ). Mean crop loss estimates ranged from $9.2 \%$ at Bhavanisagar in 1981 to $39.7 \%$ at Bijapur in 1981. The crop loss estimates at the maximum observed Striga infestation indicated that at Akola in 1982 and Bijapur in 1981 the maximum loss possible was more than $85 \%$ of the potential yield.

Estimates of loss of sorghum grain and the consequent loss in monetary terms were obtained assuming that only $10 \%$ of the hybrid sorghum growing area was affected to the levels observed in these trials (Table 4). At all-India level, the data indicated that about $53000 \mathrm{t}$ of sorghum grain worth about 67 million Indian rupees was lost every year from Striga. Among the states, $\mathrm{Ma}$ harashtre recorded losses of about $27000 \mathrm{t}$ of sorghum grain worth about 34 million Indian rupees. The monetary loss estimates were not calculated for Karnataka state because the crop loss estimates were from the post-rainy season, and the hybrid coverage is almost entirely in the rainy season. 
TABLE 4

Statewise coverage of hybrids in India and estimates of yield loss in hybrids due to Striga asiatica (average of 1980/81,1981/82 and 1982/83 statiatics)

\begin{tabular}{|c|c|c|c|c|c|c|}
\hline \multirow[t]{2}{*}{ State } & \multirow{2}{*}{$\begin{array}{l}\text { Hybrid } \\
\text { coverage } \\
\text { (\% of } \\
\text { lotal } \\
\text { area) }\end{array}$} & \multirow{2}{*}{$\begin{array}{l}\text { Area } \\
\text { covered by } \\
\text { hybrids } \\
\left(\times 10^{3} \mathrm{ha}\right)\end{array}$} & \multirow{2}{*}{$\begin{array}{l}\text { Grain } \\
\text { production } \\
\text { by hybrids } \\
\left(\times 10^{3} t\right)\end{array}$} & \multirow{2}{*}{$\begin{array}{l}\text { Estimated } \\
\text { mean } \\
\text { grain } \\
\text { yield loss } \\
(\%)\end{array}$} & \multicolumn{2}{|c|}{$\begin{array}{l}\text { Crop loss estimates assuming } \\
\text { only } 10 \% \text { of hybrid area is } \\
\text { affected }\end{array}$} \\
\hline & & & & & $\begin{array}{l}\text { Loss of grains } \\
\left(\times 10^{3} t\right)\end{array}$ & $\begin{array}{l}\text { Monetary loss } \\
\left(\times 10^{3} \mathrm{Rs}\right)\end{array}$ \\
\hline Maharashtra & 31.2 & 2044.9 & 1601.8 & 17.19 & 27.535 & 34418.75 \\
\hline Andhra Pradesh & 20.6 & 426.3 & 333.8 & 13.77 & 4.596 & 5745.00 \\
\hline Karnataka & 26.1 & 507.7 & 397.5 & $-:$ & - & - \\
\hline Madhya Pradesh' & 27.3 & 617.1 & 483.2 & 27.62 & 13.346 & 16682.50 \\
\hline Tamilnadu & 30.9 & 184.2 & 144.2 & 9.24 & 1.332 & 1665.00 \\
\hline Other states & 4.9 & 134.6 & 105.4 & - & - & - \\
\hline All-India total & 24.1 & 3913.8 & 3065.7 & 17.46 & 53.527 & 66908.75 \\
\hline
\end{tabular}

'At the all-India productivity level $\left(783.3 \mathrm{~kg} \mathrm{ha}^{-1}\right)$ for rainy season, though hybrids are known to have higher productivity levels.

${ }^{2} \mathrm{Calculated}$ at an approximate price of Rs $1250 \mathrm{t}^{-1}$ of sorghum grain. For source of statistical data, refer to Materials and methods.

"Not available for rainy season hybrid crop.

\section{DISCUSSION}

\section{Methodologies of Striga crop loss estimations}

In the past, the following 3 approaches have been used to obtain crop loss estimates from Striga.

(i) By comparing the plant/crop yield in pots/field conditions, with or without adding Striga seeds (Andrews, 1946, 1947; Younis and Agabawi, 1965). The main limitation of this approach is that the loss-estimate is at that particular level of Striga which was realized during experimentation.

(ii) By creating control vs. infested treatments in the field, where Striga plants that emerge above the ground in the control plots are removed by hand weeding (Doggett, 1965; Bebawi and Farah, 1981) or by application of 2,4-D (Last, 1960). In this procedure; Striga plants are removed or killed after emergence from the soil. As Striga does most of its damage before it emerges above the ground (Ramaiah et al., 1983), this procedure allows part of the damage effect of Striga to be included in the "no-Striga" plots leading to incorrect comparisons.

(iii) By surveys of infested fields and making visual estimate of the loss based on Striga infestation levels, soil fertility levels, moisture and degree of 
damage to the host crop. These types of estimates, which are often seen in the literature, are subjective and of limited use in crop loss predictions.

In the present study the regression approach has been used to arrive at crop loss estimates. This approach is being increasingly recognized as an important means for obtaining statistically-valid and reliable estimates of crop loss (Stynes and Veitch, 1983; Teng, 1985). A limitation is the validity of the prediction equation, which is determined by the $R^{2}$ value. However, in the present study a high $R^{2}$ value of 0.787 was obtained. It may be possible to further increase this value in future studies by monitoring soil factors like fertility, particularly nitrogen, and moisture in each plot, which could then be included as additional independent variables' in the multiple regression equation.

\section{Striga emergence and yield loss estimates}

Last (1960) and Doggett (1965), in Sudan and Tanzania, respectively, found that in Striga hermonthica 1.73-4.44 million Striga plants occur ha ${ }^{-1}$ and that only $10-30 \%$ of them emerge above the ground. The present study has used emerged Striga counts to estimate the Striga infestation. Hence there is an underlying assumption in the present study that the unknown ratio of emerged Striga plants to the total number that parasitize the host roots was the same across all the plots.

Three trials had much higher yield loss rates compared to the other 7 trials. These 3 trials were also the ones with lower Striga levels. It appeared that in these 3 trials the emergence of Striga was impeded, though the deleterious effects of the subterranean Striga plants were registered. It has generally been observed that a drought during Striga emergence reduces the number that finally emerge. It has been noticed in such instances that the delicate subterranean Striga plants dry up in the top 2-5 cm dry layer of the soil without emerging. It is possible, that, in these 3 trials, the deleterious effects of Striga were registered on the plot yields, but the Striga counts were small because of incomplete emergence of the Striga populations.

\section{Striga effects in relation to soil fertility status}

It is generally believed that Striga does not cause serious damage in highlyfertilized soil (Last, 1960; Younis and Agabawi, 1965; Pesch et al., 1983). It was clear in the present study that in the trial at ICRISAT Centre in 1982, which recorded the highest potential yield among the trials, there was significant loss from Striga. Two different aspects of fertility effects on Striga could be visualized-one on the numbers of Striga plants and another on the effects of Striga. It is known that Striga depends on its host for the nutrients taken up by the host roots (Pesch et al., 1983). Under higher fertility conditions the host could, perhaps, cope with such nutrient loss to parasite because of higher 
availability of nutrients to the roots. In the trial at ICRISAT Centre in 1982. the minimum, maximum and mean Striga numbers in the trial were high, but the potential loss estimate was only $23 \%$, the lowest among all trials. It is possible that, in this trial, the high soil fertility did not reduce Striga numbers. but reduced the Striga effects by providing higher soil nutrient levels, for which Striga depends on its host. Therefore. under higher fertility status of the soil, though the Striga numbers are not reduced, its deleterious effects are less visible.

Estimates of crop loss due to Striga

Most of the reported crop loss estimates relate to $S$. hermonthica and almost none to $S$. asiatica. With $S$. hermonthica, the crop loss estimates reported are: $50 \%$ vield loss (Last, 1960); 63.8\% loss of sorghum dry matter (Younis and Agabawi. 1965); 2-3 kg vield loss ha ${ }^{-1} 1000^{-1}$ Striga plants (Doggett, 1965); $65^{\circ} \mathrm{c}$ yield loss (Bebawi and Farah, 1981);30\% yield loss in resistant and $80 \%$ yield loss in susceptible lines (Obilana, 1983); 10-35\% yield loss (Ramaiah, 1984 ). In contrast, there are no quantified loss estimates from $S$. asiatica, though Parker (1983) quotes Sawyer (1925) that 4-46\% sorghum yield loss occurred in Burma as the result of Striga. Hosmani (1978) quoted losses of $15-100 \%$ in India with no data to substantiate the figures. However, the literature contains many statement indicating total loss from Striga in Indian farmers' and experimental fields in some years.

In the present study, the mean yield loss estimates ranged from 9.24 to $27.62 \%$ of the potential yield of the hybrid in the rainy season and 21.94 to $39.66 \%$ in the post-rainy season. In the post-rainy season in India, sorghums are grown on stored soil moisture that constantly diminishes as the season progresses. The chances of late-season rains are also small. Hence the Striga effects become cumulative in the post-rainy season and recovery because of late-season rains is low. In the rainy season, the late-season rains could allow for some recovery from Striga effects. Both at Akola and Bijapur, where trials were conducted for 3 successive years, yield loss estimates were different in each of the years indicating that seasonal effects significantly influenced crop loss estimates. The potential loss estimates indicated that a near total loss (more than $85 \%$ of the potential yield) of the sorghum crop was possible from Striga at some locations in some years. The average of the trials showed that $S$. asiatica was causing a mean loss of $17.5 \%$ to sorghum in India in the rainy season and about $25.2 \%$ mean loss in the post-rainy season, when it occurred in the intensities that were recorded in these trials. These results indicate that, if left unchecked, Striga has the potential to cause extensive loss to hybrid sorghum in India.

\section{Grain and monetary loss from Striga}

There are no known estimates of national sorghum grain loss and consequent monetary loss from Striga in India. The present study has obtained re- 
liable damage functions (percent grain loss estimates from Striga) at specific locations and years. To predict national grain yield losses, information on the extent and level of incidence of Striga in farmers' field is essential. Unfortunately, because no systematic surveys have been carried out documented evidence is not avialable on this aspect. However, it is generally known that Striga occurs in the entire sorghum-growing areas in India (ICRISAT, 1982; Vasudeva Rao et al., 1983; Vasudeva Rao, 1984) where the Striga effects are more serious on hybrids than on local varieties (ICRISAT, 1982; Vasudeva Rao, 1984). All the sorghum hybrids currently grown in India are equally (and highly) susceptible to Striga (ICRISAT, 1982). Hence in the present study loss estimates are restricted to sorghium grain produced by the hybrid cultivars in the sorghum-growing areas in India. National grain and consequent monetary loss estimates have been derived on the assumption that $10 \%$ of the hybrid sorghum area has Striga occurring at the damage levels recorded in these trials. Even at this level of occurrence, the data suggest a national annual loss of about $53000 \mathrm{t}$ of sorghum grain worth about 67 million Indian rupees (equivalent to U.S. $\$ 4.9$ million). This estimate does not include the loss occurring in Karnataka state, because in this state the damage estimates were obtained in the post-rainy season and the hybrid coverage is almost entirely in the rainy season. Striga also causes severe reduction in shoot growth, which leads to reduction in fodder yield. Fodder yield loss has not been calculated in the present study. Hence the real monetary loss is probably more than estimated. This significant loss figure suggests the need for intensified research efforts to reduce the Striga menace on hybrid sorghums in India. It is possible that in other countries where Striga is present similar losses in yields of sorghum and other hosts occur.

\section{ACKNOWLEDGEMENTS}

The authors wish to acknowledge S.T. Khade, A. Puttarudrappa, V.K. Shinde and A.R. Dabholkar, Sorghum Breeders, for their help in conducting the trials at Akola, Bijapur, Parbhani and Indore, respectively; $\mathbf{M}$. Singh and $\mathbf{P}$. Venkateshwarlu for advice and help in statistical analysis; D.S. Murthy and R.P. Singh for their comments on the contents of this paper; R.V. Vidyabhushanam and B.V.S. Reddy for supplying the production statistics.

This paper was submitted as ICRISAT Journal Article J.A. 718.

\section{REFERENCES}

Andrews, F.W., 1946. Parasitism of Striga sp. on Dolichos lablab L. Nature (London), 157: 515. Andrews, F.W., 1947. Paresitism of Striga hermonthica on leguminous plants. Ann. Appl. Biol., 34: 267-275. 
Bebawi, F.F. and Farah. A.F., 1981. Effects of parasitic and non-parasitic weeds on Sorghum bicolor. Exp. Agric. 17: 415-418.

Digby, P.G.N., 1979. Modified joint regression analysis for incomplete variety $\times$ environment data. J. Agric. Sci. (Cambridge), 93: 81-86.

Doggett. H., 1965. Striga hermonthica on sorghum in East Africa. J. Agric. Sci., 65: 183-194.

Government of India, 1984. Ministry of Agriculture, Depertment of Agriculture and Cooperation. Jowar. In: Area and Production of Principal Crops in India 1981-84. New Delhi, India, Controller of Publications. pp. 80-89.

Hosmani, M.M., 1978. Striga-a noxious root parasite. University of Agricultural Sciences, Bangalore, India. pp. 165.

ICRISAT, 1982. Proceedings of ICRISAT-AICSIP(ICAR) Working Group Meeting on Striga Control, ICRISAT Centre, 30 September-1 October 1982, Departmental Report (SB-4) Sorghum Breeding, ICRISAT, Patancheru, A.P., India.

Last, F.T.. 1960. Effect of cultural treatments on incidence of Striga hermonthica (Del.) Benth. and yields of sorghum in the Sudan: field experiments 1957/58. Ann. Appl. Biol., 40: 207-229.

Obilana, A.T., 1983. Striga studies and control in Nigeria. In: Proceedings of the Second Inter. national Workshop on Striga, 5-8 October 1981, Ougadougou, Upper Volta. ICRISAT, Pa. tancheru, A.P., India, pp. 87-98.

Parker, C., 1983. Striga-analysis of past research and summary of the problem. In: Proceedings of the Second International Workshop on Striga, 5-8 October 1981, Ougadougou. Upper Volta. ICRISAT, Patancheru, A.P., India. pp. 9-16.

Pesch, C., Pieterse, A.H. and Stoop. W.A., 1983. Inhibition of germination in Striga by means of urea. In: Proceedings of the Second International Workshop on Striga, 5-8 October 1981, Ougadougou, Upper Volta. ICRISAT, Patancheru, A.P., India, pp. 37-38.

Ramaiah, K.V., 1984. Patterns of Striga resistance in sorghum and millets with special emphasis on Africa. In: Proceedinge of Workshop on the Biology and Control of Striga, 14-17 November 1983, Dakar, Senegal. ICSU Press, Paris and IDRC, Ottawa, pp. 71-92.

Ramaiah, K.V., Parker. C., Vasudeva Rao, M.J. and Musselman, L.J., 1983. Striga Identification and Control Handbook. ICRISAT, Patancheru, A.P., India, 52 pp.

Stynes, B.A. and Veith, L.G., 1983. Determining crop losses-a complex regression problem. In: Proceedings of the Fourth International Congress of Plant Pathology, 17-24 August 1983, Melbourne, Australia, p. 4.

Teng. P.S., 1985. Construction of predictive models: II. Forecasting crop losses. Adv. Plant Pathol., 3: 179-206.

Vasudeva Rao, M.J., 1984. Patterns of resistance to Striga asiatica in sorghum and millets, with special reference to Asia. In: Striga: Biology and Control. Paper presented at a Workshop on the Biology and Control of Striga, 14-17 November 1983, Dakar, Senegal. ICSU Presa, Paris, France and IDRC, Ottawa, Canada.

Vasudeva Rao, M.J., 1987. Techniques for screening sorghoms for resistance to Striga. In: L.J. Musselman (Editor), Parasitic Weeds in Agriculture I. Striga. CRC Press, Boca Raton, Florida, pp. 281-304.

Vasudeva Rao, M.J.. Chidley, V.L., Ramaiah, K.V. and House, L.R., 1983. Breeding sorghum with resistance to Striga asiatica at ICRISAT Centre. In: Proceedings of the Second International Workshop on Striga, 5-8 October 1981. ICRISAT, Patancheru, A.P., India, pp. 61-76.

Yates, F. and Cochran, W.G., 1938. The analysis of groups of experiments. J. Agric. Sci. (Cambridge ), 28: 556-580.

Younis, A.E. and Agabawi, K.A., 1965. Effect of Striga hermonthica Benth. and nitrogen application on the growth and nitrogen content of Sorghum vulgare L. Acta Biol. (Hungary). 15: 361-369. 